\section{RMD Open}

Rheumatic \&

Musculoskeletal Diseases

\title{
Diagnostic impact of routine Lyme serology in recent-onset arthritis: results from the ESPOIR cohort
}

\author{
Dewi Guellec, ${ }^{1,2}$ Valérie Narbonne, ${ }^{3}$ Divi Cornec, ${ }^{1}$ Thierry Marhadour, ${ }^{1}$ \\ Sophie Varache, ${ }^{1}$ Maxime Dougados, ${ }^{4}$ Jean Pierre Daurès, ${ }^{5}$ \\ Sandrine Jousse-Joulin, ${ }^{1}$ Valérie Devauchelle-Pensec, ${ }^{1}$ Alain Saraux ${ }^{1}$
}

To cite: Guellec D,

Narbonne V, Cornec D, et al. Diagnostic impact of routine Lyme serology in recentonset arthritis: results from the ESPOIR cohort. RMD Open 2016;1:e000120. doi:10.1136/rmdopen-2015000120

- Prepublication history for this paper is available online. To view these files please visit the journal online (http://dx.doi.org/10.1136/ rmdopen-2015-000120).

Received 22 April 2015 Revised 22 July 2015 Accepted 27 September 2015

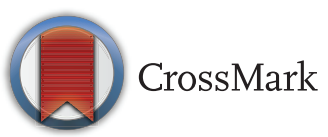

For numbered affiliations see end of article.

Correspondence to Dr Alain Saraux; alain.saraux@chu-brest.fr

\section{ABSTRACT}

Objectives: Lyme disease may be considered by rheumatologists in patients with recent-onset arthritis, even in the absence of suggestive symptoms. The aim of this study was to determine the diagnostic impact of routine Lyme serology in a French cohort of patients with recent-onset arthritis affecting at least 2 joints.

Methods: We performed an ancillary study of a French prospective multicentre cohort established to monitor clinical, biological and radiographic data in patients with inflammatory arthritis in at least 2 joints, lasting for 6 weeks to 6 months. Borrelia $\lg M$ and $\lg G$ antibodies were sought routinely at baseline, using ELISA tests, independently from the physician's strategy for detecting a spirochetal infection. We recorded the proportion of patients with a final diagnosis of Lyme arthritis and evaluated the diagnostic performance of Lyme serology in this particular context. The clinical and biological characteristics of patients according to the Lyme serology results were analysed.

Results: Of 810 patients, $657(81.1 \%)$ were negative for IgM and IgG antibodies, 91 (11.2\%) had only IgM antibodies, $49(6 \%)$ had only IgG antibodies, and 13 $(1.6 \%)$ had $\operatorname{lgG}$ and $\lg M$ antibodies. Thus, $7.6 \%$ had IgG positivity, consistent with exposure to Borrelia infection. IgG positivity was significantly more prevalent in the North and North-East regions of France $\left(\chi^{2}=14.6, p<0.001\right)$. No patients received a definite diagnosis of Lyme arthritis.

Conclusions: This study does not support routine Lyme serological testing in patients with recent-onset inflammatory arthritis affecting more than 1 joint.

\section{INTRODUCTION}

Lyme disease is an infection due to the spirochete Borrelia and spreads to humans by infected Ixodes ticks. It is the most common arthropod-borne disease in temperate regions of the northern hemisphere. In the USA, Borrelia burgdorferi sensu stricto is the only species responsible for Lyme disease.

\section{Key messages \\ What is already known on this subject? \\ - Lyme serology is not recommended as a routine test in patients with recent-onset arthritis affect- ing more than one joint but some rheumatolo- gists prescribe it in this context. \\ What does this study add? \\ - This study confirms that more than $10 \%$ of patients with recent-onset arthritis not due to Lyme disease have positive Lyme serological tests. \\ How might this impact on clinical practice? \\ - Routine Lyme serology is unnecessary in this context.}

In Europe and Asia, the disease can be due to at least two additional genospecies: Borrelia afzelii and Borrelia garinii. All genospecies known to cause Lyme disease are regrouped in the Borrelia burgdorferi sensu lato complex. Risk factors for Lyme disease include occupational and recreational activities in grassy or wooded areas. ${ }^{1}$ In Europe, incidence rates range across countries from less than 1/100 000 (England, Portugal and Turkey) to about 350/100 000 population (Austria). ${ }^{2}$ In France, the disease occurs in all regions except the Mediterranean rim and high mountains, with an overall annual incidence estimated at 16/100 000 population and several endemic areas, such as Alsace, where the incidence reaches 250/100000 population. $^{3}$

Erythema migrans (EM) is the most common manifestation of Lyme disease. It begins 2-32 days after the bite as a red macule and expands over days to weeks to an erythematous annular lesion of $5 \mathrm{~cm}$ to greater than $68 \mathrm{~cm}$. It may be accompanied with a flu-like syndrome. EM is typical but 
may be absent or missed in $20-30 \%$ of cases, delaying the diagnosis of Lyme disease until the infection disseminates into other organs. ${ }^{4}$ Several weeks or months after the inoculation, untreated patients may experience systemic manifestations such as neuroborreliosis (meningoradiculitis, meningitis or meningoencephalitis), arthritis or Borrelia lymphocytoma. Multiple EM lesions and cardiac manifestations are less common. Months to years after the inoculation, acrodermatitis chronica atrophicans, lymphocytoma, chronic arthritis, encephalomyelitis or chronic neuroborreliosis may develop. ${ }^{25}$

During the early stages of Lyme disease, non-specific arthralgia may occur in up to $70 \%$ of cases. Lyme arthritis may develop at the early or late stage of dissemination. The typical presentation, concerning more than 90\% of patients with Lyme arthritis, is relapsing/remitting monarthritis or oligoarthritis that chiefly affects the large joints, most notably the knee. Other rare presentations such as polyarthritis and polyarthralgia have been reported in up to $6 \%$ of cases. ${ }^{6}$ Joint erosions have been observed in some patients with longstanding untreated infection or antibiotic-unresponsive disease. ${ }^{7}$ In cases of suspected Lyme arthritis, it is recommended to perform an ELISA test and to confirm it by a Western blot test. High levels of IgG antibodies are usually detected. Synovial fluid/tissue culture and PCR are optional.

To date, Lyme serology is not recommended as a routine test in patients with recent-onset arthritis affecting more than one joint and lasting for several weeks. However, rheumatologists sometimes consider Lyme arthritis as a differential diagnosis in this group of patients, even in non-endemic regions and in the absence of typical articular manifestations or extraarticular symptoms. ${ }^{8}$ Given the high proportion of Borrelia-infected patients who do not develop EM, the increasing incidence of Lyme disease in several areas, as well as the broad spectrum of the joint manifestations of Lyme arthritis and the diagnostic usefulness of routine Lyme serology in patients with recent-onset arthritis, deserves investigation.

Here, our aim was to determine the diagnostic usefulness of routine Lyme serology in a French cohort of patients with recent-onset arthritis affecting more than one joint. We evaluated the prevalence of Borrelia antibodies in each geographic region, the prevalence of Lyme arthritis and the diagnostic accuracy of Lyme serology. We also assessed whether Lyme serology results were influenced by clinical or biological parameters related to the inflammatory arthritis or general health status.

\section{METHODS}

\section{Study population}

We conducted an ancillary study of data from the French prospective multicentre ESPOIR cohort established to monitor clinical, biological and radiographic data from patients with recent-onset inflammatory arthritis affecting more than one joint. General practitioners and rheumatologists referred patients to 14 centres in 10 regions throughout France. Patient inclusion occurred from December 2002 to March 2005. ${ }^{9}$

Patients were eligible if they were 18-70 years of age and had either a definitive or probable clinical diagnosis of rheumatoid arthritis or polyarthritis not better explained by another aetiology. Additional inclusion criteria were swelling of at least two joints for 6 weeks to 6 months and no prior treatment with disease-modifying antirheumatic drugs (DMARDs) or glucocorticoids; however, glucocorticoid therapy in a mean dosage $\leq 20 \mathrm{mg}$ /day given for $\leq 2$ weeks and discontinued at least 2 weeks earlier was allowed.

The study was approved by the institutional review board of the Montpellier University Hospital, the coordinating centre for this nationwide study. Before inclusion, all patients gave their written informed consent to study participation.

\section{Study design}

The baseline assessment included a standardised interview; a general physical examination; blood cell counts; kidney function tests; viral serological tests (parvovirus $\mathrm{B} 19$, hepatitis $\mathrm{B}$ and $\mathrm{C}$ viruses, HIV); immunological tests (ELISAs for IgM, IgG and IgA rheumatoid factors and tests for anticitrullinated peptide antibodies (ACPAs) and antinuclear antibodies (ANAs)), HLA DR phenotype determination; a cytokine profile (IL-1R $\alpha$, IL-6, IL-10, MCP-1, IL-4, IL-17, IFN $\gamma$, TNF $\alpha$, IL-16 and IL-2); urine tests; radiographs of the chest, pelvis, hands and feet in the posteroanterior view; and radiographs of the feet in the oblique view. Renal failure was arbitrarily defined as serum creatinine $>110 \mu \mathrm{mol} / \mathrm{L}$. Activity of the inflammatory arthritis was assessed at baseline through the disease activity score on 28 joints (DAS28) and the Ritchie index of joint tenderness, validated in the assessment of RA. Each patient was routinely evaluated by an ESPOIR study rheumatologist every 6 months for 2 years and then once a year for at least 10 years.

Antibodies against Borrelia were sought routinely in 2006, using IgG and IgM ELISAs (EuroImmun, BioAdvance, Philadelphia, Pennsylvania, USA) on blood samples collected, stored $\left(-80^{\circ} \mathrm{C}\right)$ and centralised at inclusion into the cohort. Western blot confirmation was not obtained routinely as part of this project. All serological tests were conducted at the microbiology unit of the Brest university hospital, after the end of patient inclusion, independently from the physician's strategy for detecting a possible spirochetal infection at the first visit or during follow-up. Neither the investigators nor the patients were informed of the results of routine serological testing.

\section{Diagnosis of Lyme arthritis}

For each patient, we reviewed the most likely diagnosis at the first visit, the diagnosis recorded after 2 years of 
follow-up, and all the information available after the last visit. We used these data to determine whether Lyme arthritis as the cause of the baseline disease presentation was confirmed, suspected or excluded. Thus, there was no standardisation of the procedure to confirm the diagnosis of Lyme arthritis. The decision to perform ELISA, Western blot and/or PCR tests to confirm the diagnosis of Lyme arthritis was up to the rheumatologist in charge of the patient.

\section{Statistical analysis}

We first recorded the prevalence of Lyme antibodies at baseline in the overall population and in subgroups defined by geographic area of residence. We considered that a diagnosis of Lyme arthritis could not be excluded on the basis of serology in patients with IgG positivity. Isolated IgM positivity was not considered as suggestive of Lyme arthritis according to articular symptoms duration. We determined the proportion of patients with a final diagnosis of Lyme arthritis and the diagnostic accuracy of Lyme serology in patients with recent-onset arthritis. Potential associations linking baseline clinical and biological characteristics to Lyme serology results were assessed using SPSS V.21.0 software (SPSS Inc, Chicago, Illinois, USA). We used the $\chi^{2}$ test or Fisher's exact test, as appropriate, or the Mann-Whitney test. According to Bonferroni's correction for multiple comparisons, only $p$ values $\leq 0.002$ were considered statistically significant.

\section{RESULTS}

Lyme serology results in the overall cohort and in each geographic area

Among the 814 patients included in the ESPOIR cohort, $810(99.5 \%)$ were tested for Borrelia antibodies. Among them, $657(81.1 \%)$ were negative for IgM and IgG antibodies, $91(11.2 \%))$ had only IgM antibodies, $49(6 \%)$ had only IgG antibodies, and $13(1.6 \%)$ had IgM and IgG antibodies. Thus, $62(7.6 \%)$ patients had results that did not exclude the possibility of Lyme arthritis (IgG with or without IgM antibodies) (table 1).

The prevalence of IgG antibodies varied significantly by geographic area of residence (from $2.4 \%$ to $14.9 \%$ ) (figure 1). Prevalence was highest in Alsace (14.9\%), the region of highest endemicity in France. A high prevalence of $12 \%$ was also found in the Ile-de-France region. Four of the 10 regions had prevalences lower than 5\% (Bretagne, 3.8\%; Centre, 2.9\%; Midi-Pyrénées, 2.6\%; and Languedoc-Roussillon, 2.4\%). IgG antibodies were significantly more prevalent in the northern and northeastern parts of France than in the other regions $\left(\chi^{2}=14.6, \mathrm{p}<0.001\right)$.

\section{Diagnostic accuracy of Lyme serology in patients with recent-onset arthritis}

Lyme arthritis was initially suspected in two patients but was confirmed in neither. Moreover, the prospective follow-up has secured an alternative diagnosis in both patients. Thus, in the cohort of 810 patients, routine Lyme serology incorrectly suggested the possibility of Lyme arthritis in $7.6 \%$ of patients. Table 2 details the final diagnoses in the patients with positive Lyme serology results.

\section{Factors influencing Lyme serology results}

The final diagnosis given after 2 years of follow-up was not significantly different between patients with and without positive Lyme serological tests. Body weight was significantly lower in IgM-positive than in IgM-negative patients ( 65.0 vs $68.7 \mathrm{~kg}, \mathrm{p}=0.02$ ). IgG positivity was significantly associated with higher values of the mean Ritchie index for joint tenderness ( 24.3 vs $17.1, \mathrm{p}=0.002$ ) and non-significantly associated with higher values of the mean DAS28 (5.4 vs 5.1, p=0.05) (table 3).

The proportion of patients with lymphopenia was higher among the patients with IgM and IgG antibodies than among the other patients (3/13 vs $47 / 796$, $\mathrm{p}=0.04)$. The mean erythrocyte sedimentation rate was higher in IgM-positive than in IgM-negative patients (33.8 vs $28.8 \mathrm{~mm} / \mathrm{h}, \mathrm{p}=0.05$ ), whereas no differences were found across subgroups for $\mathrm{C}$ reactive protein levels. The proportion of patients with renal failure was higher in patients who had IgG antibodies with or without IgM antibodies compared with the other patients $(5 / 60$ vs $12 / 738, \mathrm{p}=0.006$; and $2 / 13$ vs $15 / 785$,

Table 1 Lyme serology results according to the region of inclusion

\begin{tabular}{|c|c|c|c|c|c|}
\hline Region & IgM-/lgG- & IgM+/lgG- & lgM-/lgG+ & lgM+/lgG+ & Total \\
\hline Alsace & $59(79.7 \%)$ & $4(5.4 \%)$ & 9 (12.2\%) & $2(2.7 \%)$ & 74 \\
\hline Aquitaine & $30(85.7 \%)$ & $3(8.6 \%)$ & $2(5.7 \%)$ & $0(0 \%)$ & 35 \\
\hline Bretagne & $38(71.7 \%)$ & $13(24.5 \%)$ & $2(3.8 \%)$ & $0(0 \%)$ & 53 \\
\hline Centre & $64(92.7 \%)$ & $3(4.3 \%)$ & $1(1.4 \%)$ & $1(1.4 \%)$ & 69 \\
\hline Haute-Normandie & $66(84.6 \%)$ & $7(9 \%)$ & $5(6.4 \%)$ & $0(0 \%)$ & 78 \\
\hline Ile-de-France & $193(77.2 \%)$ & $27(10.8 \%)$ & $24(9.6 \%)$ & $6(2.4 \%)$ & 250 \\
\hline Languedoc-Roussillon & $64(79 \%)$ & $15(18.5 \%)$ & 1 (1.2\%) & $1(1.2 \%)$ & 81 \\
\hline Midi-Pyrénées & $64(83.1 \%)$ & $11(14.3 \%)$ & $0(0 \%)$ & $2(2.6 \%)$ & 77 \\
\hline Nord-Pas-de-Calais & $44(81.5 \%)$ & $6(11.1 \%)$ & $4(7.4 \%)$ & $0(0 \%)$ & 54 \\
\hline Picardie & $35(89.7 \%)$ & $2(5.1 \%)$ & $1(2.6 \%)$ & $1(2.6 \%)$ & 39 \\
\hline Overall & $657(81.1 \%)$ & $91(11.2 \%)$ & $49(6 \%)$ & $13(1.6 \%)$ & 810 \\
\hline
\end{tabular}


Figure 1 Prevalence of $\lg G$ antibodies according to the region of inclusion (map produced by DrawMeAGraph.com). The white areas correspond to regions with no data. The green areas correspond to regions with available data, the colour intensity being proportional to the prevalence of IgG antibodies.

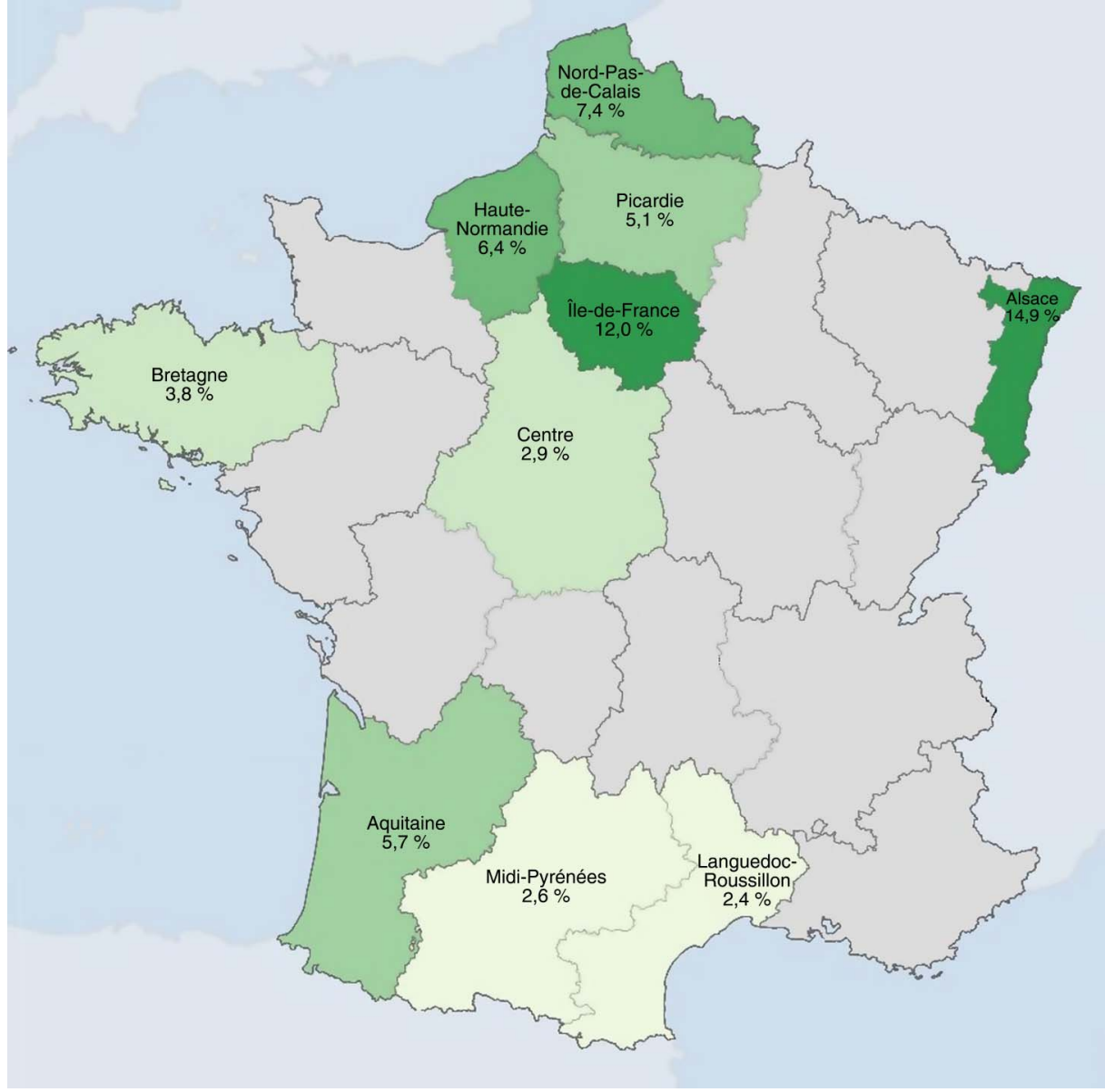

Table 2 Final diagnoses of patients with positive Lyme serology

\begin{tabular}{ll}
\hline Serological results & Final diagnoses \\
\hline IgM+/lgG+ (13 patients) & 9 Rheumatoid arthritis \\
& 2 Unclassified arthritis \\
& (Including 1 transient inflammatory arthritis that recovered after NSAID use and 1 chronic \\
& inflammatory arthritis controlled by methotrexate) \\
& 1 Sjögren's syndrome \\
& 1 Viral arthritis \\
& 37 Rheumatoid arthritis \\
& 7 Spondyloarthritis \\
& 3 Unclassified arthritis \\
& (Including 2 undifferentiated arthritis controlled by DMARDs+NSAID and 1 transient inflammatory \\
& arthritis with immune profile evocative of RA) \\
& 2 Sjögren's syndrome \\
IgM-/lgG+ (49 patients) & 68 Rheumatoid arthritis \\
& 12 Unclassified arthritis \\
& 4 Spondyloarthritis \\
& 2 Osteoarthritis \\
& 1 Viral arthritis \\
& 1 Systemic lupus erythematosus \\
& 1 Complex regional pain syndrome \\
& 1 Sjögren's syndrome \\
& 1 Hepatitis C virus-related cryoglobulinaemic vasculitis \\
&
\end{tabular}

DMARDs, disease-modifying antirheumatic drugs; NSAID, non-steroidal anti-inflammatory drug; RA, rheumatoid arthritis. 
Table 3 Clinical and biological parameters according to Lyme serology results

\begin{tabular}{|c|c|c|c|c|c|c|c|c|c|c|c|c|}
\hline Features & $\lg M+$ & $\lg M-$ & $\begin{array}{l}p \\
\text { Value }\end{array}$ & $\lg G_{+}$ & $\lg \mathbf{G}-$ & $\begin{array}{l}p \\
\text { Value }\end{array}$ & $\begin{array}{l}\lg M+\text { and/or } \\
\lg G+\end{array}$ & $\begin{array}{l}\text { Not lgM+ } \\
\text { and/or lgG+ }\end{array}$ & $\begin{array}{l}\mathbf{p} \\
\text { Value }\end{array}$ & $\begin{array}{l}\lg M+\text { and } \\
\lg G_{+}\end{array}$ & $\begin{array}{l}\text { Not } \lg M+\text { and } \\
\lg G_{+}\end{array}$ & $\begin{array}{l}\mathbf{p} \\
\text { Value }\end{array}$ \\
\hline $\begin{array}{l}\text { Females, } \mathrm{n} / \mathrm{N} \\
(\%)\end{array}$ & $85 / 104(81.7)$ & $536 / 706$ & 0.21 & $43 / 62(69.3)$ & $578 / 748$ & 0.16 & 118/153 (77.1) & $503 / 657(76.6)$ & 0.92 & $10 / 13(76.9)$ & $611 / 797$ (76.7) & $1^{*}$ \\
\hline $\begin{array}{l}\text { Weight }(\mathrm{kg}) \text {, } \\
\text { mean }(\mathrm{SD})\end{array}$ & $65(11.7)$ & $68.7(14.1)$ & 0.02 & $68.5(14.3)$ & $68.2(13.8)$ & 0.88 & $66.5(13.0)$ & $68.6(14.0)$ & 0.09 & $64.1(10.1)$ & $68.3(13.9)$ & 0.50 \\
\hline $\begin{array}{l}\text { Ritchie's index, } \\
\text { mean (SD) }\end{array}$ & $17.9(17.7)$ & $17.6(17.2)$ & 0.56 & $24.3(21.1)$ & $17.1(17.1)$ & 0.002 & $19.9(20.0)$ & $17.1(16.8)$ & 0.19 & $24.5(25.5)$ & $17.5(17.3)$ & 0.29 \\
\hline $\begin{array}{l}\text { DAS28, mean } \\
\text { (SD) }\end{array}$ & $5.2(1.3)$ & $5.1(1.3)$ & 0.78 & $5.4(1.4)$ & $5.1(1.3)$ & 0.05 & $5.2(1.4)$ & $5.1(1.3)$ & 0.26 & $5.5(1.0)$ & $5.1(1.3)$ & 0.15 \\
\hline $\begin{array}{l}\text { Lymphopenia } \\
<1000 / \mathrm{mm}^{3}, \\
\mathrm{n}(\%)\end{array}$ & 9/104 (8.6) & 41/705 (5.8) & 0.26 & 7/62 (11.3) & $43 / 747(5.8)$ & $0.09^{*}$ & 13/153 (85.0) & $37 / 656(5.6)$ & 0.19 & $3 / 13(23.1)$ & 47/796 (5.9) & $0.04^{*}$ \\
\hline $\begin{array}{l}\text { Neutrophils } \\
>7000 / \mathrm{mm}^{3} \text {, } \\
\mathrm{n}(\%)\end{array}$ & 88/103 (85.4) & 606/697 (86.9) & 0.67 & $52 / 62(83.9)$ & 642/738 (87.0) & 0.44 & 128/152 (84.2) & $566 / 648(87.3)$ & 0.30 & 12/13 (92.3) & $682 / 787$ (86.7) & $1^{*}$ \\
\hline ESR, mean (SD) & $33.8(26.6)$ & $28.8(24.3)$ & 0.05 & $30.9(26.0)$ & $29.3(24.5)$ & 0.86 & 32.7 (26.2) & $28.7(24.2)$ & 0.09 & $32.9(28.6)$ & $29.4(24.6)$ & 0.74 \\
\hline $\begin{array}{l}\text { CRP (IU/L), } \\
\text { mean (SD) }\end{array}$ & $19.1(32.0)$ & $20.4(32.5)$ & 0.30 & $22.8(37.0)$ & $20.0(32.0)$ & 0.30 & $20.2(34.1)$ & $20.3(32.0)$ & 0.44 & $23.3(32.4)$ & $20.2(32.4)$ & 0.84 \\
\hline $\begin{array}{l}\text { Serum creatinine } \\
>110 \mu \mathrm{mol} / \mathrm{L}, \\
\mathrm{n} / \mathrm{N}(\%)\end{array}$ & 3/104 (2.9) & 14/694 (2.0) & $0.48^{\star}$ & $5 / 60(8.3)$ & 12/738 (1.6) & $0.006^{\star}$ & 6/151 (4.0) & $11 / 647(1.7)$ & $0.11^{*}$ & 2/13 (15.4) & $15 / 785$ (1.9) & $0.03^{*}$ \\
\hline $\begin{array}{l}\text { RF (IU/L), mean } \\
\text { (SD) }\end{array}$ & $94.1(205.4)$ & $123.6(583.8)$ & 0.01 & $117.3(273.2)$ & $120.0(567)$ & 0.84 & $106.7(240.11)$ & $122.9(599.7)$ & 0.02 & $57.3(101.7)$ & $120.8(554.3)$ & 0.65 \\
\hline $\begin{array}{l}\text { ACPA (IU/L), } \\
\text { mean (SD) }\end{array}$ & $428.9(1096.0)$ & $486.6(1491.8)$ & 0.98 & 389.7 (935.4) & 486.6 (1481.2) & 0.37 & $440.5(1072.8)$ & $488.2(1521.0)$ & 0.88 & $104.9(267.9)$ & $485.3(1457.2)$ & 0.17 \\
\hline
\end{tabular}


$\mathrm{p}=0.03$, respectively). Mean rheumatoid factor titres were lower in the IgM-positive subgroup than in the other patients (94.1 vs $123.6 \mathrm{IU} / \mathrm{L}, \mathrm{p}=0.01$ ) (table 3). None of these differences was significant after Bonferroni's correction.

\section{DISCUSSION}

Routine Lyme serology was not useful for detecting cases of Lyme arthritis in French patients with recent-onset arthritis affecting more than one joint, as defined in the ESPOIR cohort. Thus, although $7.6 \%$ of patients had results that did not exclude the possibility of Lyme arthritis, no patients were given a definite diagnosis of Lyme arthritis. Among the clinical or laboratory features studied, only the Ritchie index was significantly associated with Lyme serology results after Bonferroni's correction. The prevalence of Borrelia antibodies varied widely across geographic regions of France.

Another study used less restrictive criteria than ours to include 90 patients who had arthritis onset within the last year and lived in non-endemic areas of France. ${ }^{10}$ None of the patients had positive Lyme serology results or a definite diagnosis of Lyme arthritis. A 2013 abstract reported a $4.5 \%$ seroprevalence of Lyme antibodies among 1180 patients who presented to the Leiden Early Arthritis Clinic in the Netherlands, including $8(0.7 \%)$ given a definite diagnosis of Lyme arthritis. ${ }^{11}$ The estimated positive predictive value was $10-28 \%$ overall but increased to $67 \%$ when the analysis was confined to patients with monarthritis or oligoarthritis chiefly involving the large joints. Together with our results, these results do not support routine Lyme serology in patients with recent-onset arthritis affecting more than one joint and lasting for several weeks. Instead, the clinical features should be taken into account to determine whether Lyme serology is in order at the individual level. The apparently better performance of Lyme serology in the Leiden cohort should be interpreted in the light of the difference in Lyme disease prevalence between France and the Netherlands. Lyme disease is endemic in the Netherlands, where the estimated annual incidence is $133 / 100000$ population. ${ }^{12}{ }^{13}$ In addition, the restrictive criteria used to select the ESPOIR cohort patients excluded patients with monarthritis at the first visit and therefore probably led to the exclusion of typical Lyme arthritis cases. Overall, French patients with inflammatory arthritis affecting more than one joint and lasting for more than 6 weeks are not likely to have authentic Lyme arthritis.

That $7.6 \%$ of patients had positive serological tests yet none had definite Lyme arthritis deserves discussion. This global prevalence is within the limits of that usually found in French patients benefitting from Lyme serology (6-8.5\%). However, in these selected populations, individuals are more likely to have authentic Lyme disease. The prevalence of IgG antibodies was highest $(14.9 \%)$ in Alsace, the area of greatest endemicity in
France, ${ }^{3}$ and was higher in northern and north-eastern France than in other areas, in keeping with the previously described East-West and North-South gradients in the incidence of Lyme disease. ${ }^{14}$ These results suggest that some patients had acquired IgG antibodies during previous contact with Borrelia. Thus, in areas where Borrelia is prevalent in the tick population, routine Lyme serology as an aetiological assessment tool for recent-onset arthritis may carry a high risk of misleading results. Its use could increase the prescription of unnecessary and costly confirmatory tests and possibly the number of erroneous diagnoses of Lyme arthritis, leading to unnecessary treatments with antibiotics. Another explanation to the high proportion of positive serological tests, particularly for IgM antibodies, in patients without Lyme arthritis, involves a role for the technical characteristics of the ELISAs used and for the clinical setting in which the tests were performed. Among healthy persons living in regions of low endemicity, Lyme serological tests have an estimated falsepositive rate of $2-5 \% .{ }^{15-17}$ The most common infectious reasons for positive Lyme serology in patients without definite Lyme disease are other spirochetal infections such as syphilis, spirochetal periodontal disease and relapsing fever. ${ }^{18} 19$ None of these infections were documented in any of the patients with positive Lyme serology in the ESPOIR cohort. Rheumatic diseases can also lead to false-positive Lyme tests, especially for IgM antibodies, ${ }^{15-17}$ a fact that probably explains the substantial number of IgM-positive patients in our cohort.

Patients with positive Lyme serology did not differ from the other patients regarding the final diagnosis. However, patients with positive Lyme serology had higher values of several parameters reflecting the clinical or biological activity of inflammatory arthritis, including the Ritchie joint tenderness index, DAS28, and erythrocyte sedimentation rate; in contrast, rheumatoid factor titres were lower. After Bonferroni's correction, the only significant difference was for the Ritchie index, which was significantly higher in IgG-positive patients. Conceivably, patients with recent-onset arthritis who have specific immune profiles may be more likely to develop non-specific antibodies responsible for crossreactivity. ${ }^{20}$ However, these results should be interpreted with caution due to the small number of patients constituting the groups defined by the positivity of Lyme serology.

Our study has several limitations. First of all, the diagnosis of Lyme arthritis was not standardised and no confirmatory Western blots were routinely performed in patients with positive ELISAs. Although unlikely, the possibility of undiagnosed Lyme arthritis cases within the ESPOIR cohort remains questionable. Also, individuals with monarthritis were not included in the ESPOIR cohort, while it is the most common initial manifestation of Lyme arthritis. As a result, our findings are limited to the specific cases of recent-onset arthritis affecting two or more joints. 


\section{CONCLUSION}

This study does not support routine Lyme serological testing in patients with recent-onset inflammatory arthritis affecting more than one joint. Previous contact with Borrelia burgdorferi and background false-positivity due to the immunological setting may cause difficulties in interpreting the results of Lyme serological tests. When seeking to determine the cause of recent-onset oligoarthritis or polyarthritis, the appropriateness of Lyme serological testing should be determined on the basis of the history of a tick bite and/or EM and on the distribution of the arthritis.

\section{Author affiliations}

${ }^{1}$ Department of Rheumatology, CHU de la Cavale Blanche, Boulevard Tanguy Prigent, Brest, France

2EA 2216, INSERM ESPRI, ERI29 Université Bretagne Occidentale, Brest, France

${ }^{3}$ Department of Microbiology, CHU de la Cavale Blanche, Boulevard Tanguy Prigent, Brest, France

${ }^{4}$ Department of Rheumatology-Hôpital Cochin, Assistance PubliqueHôpitaux de Paris INSERM (U1153): Clinical Epidemiology and Biostatistics, PRES Sorbonne Paris-Cité, Paris, France

${ }^{5}$ Department of Biostatistics, Clinical Research Institute, University of Montpellier, 641 av. du doyen G. Giraud, Montpellier 34093, Nimes, France

\section{Twitter Follow Alain Saraux at @alain.saraux}

Acknowledgements The authors thank Nathalie Rincheval who was in charge of study monitoring and data management, as well as the investigators who recruited and followed the patients in Amiens ( $\mathrm{P}$ Fardellone and $\mathrm{P}$ Boumier), Bordeaux (T Schaeverbeke), Brest (A Saraux), Lille (RM Flipo), Montpellier (B Combe and H Cholvy-Nicolas), Paris-Bicêtre (X Mariette and F Desmoulins), Paris-Bichat (0 Meyer and G Hayem), Paris-Cochin (M Dougados), Paris-La Pitié (B Fautrel and B Banneville), Paris-St Antoine (F Berenbaum and S Le Gars), Rouen (X Le Loët, and 0 Vittecoq), Strasbourg (J Sibilia), Toulouse (A Cantagrel) and Tours (P Goupilleand S Mammou). They also thank Dorothé Quinio for contributing to the Lyme serological testing.

Funding An unrestricted grant from Merck Sharp and Dohme (MSD) supported the first 5 years of the ESPOIR cohort study. The biological database was supported in part by two grants from the INSERM. The French Society for Rheumatology, Pfizer, Abbvie and Roche-Chugai also supported the ESPOIR cohort study. Institutional support was received from Abbott for the serological tests.

Competing interests None declared.

Patient consent Obtained.

Ethics approval CCP Montpellier.

Provenance and peer review Not commissioned; externally peer reviewed.

Data sharing statement Studies conducted on the ESPOIR cohort are available on http://www.lacohorteespoir.fr
Open Access This is an Open Access article distributed in accordance with the Creative Commons Attribution Non Commercial (CC BY-NC 4.0) license, which permits others to distribute, remix, adapt, build upon this work noncommercially, and license their derivative works on different terms, provided the original work is properly cited and the use is non-commercial. See: http:// creativecommons.org/licenses/by-nc/4.0/

\section{REFERENCES}

1. Shapiro ED. Lyme disease. N Engl J Med 2014;371:684.

2. Rizzoli A, Hauffe H, Carpi G, et al. Lyme borreliosis in Europe. Euro Surveill 2011;16:pii19906.

3. Mariet AS, Retel O, Avocat $\mathrm{H}$, et al. Estimated incidence of erythema migrans in five regions of France and ecological correlations with environmental characteristics. Vector Borne Zoonotic Dis 2013;13:666-73.

4. Steere AC, Sikand VK. The presenting manifestations of Lyme disease and the outcomes of treatment. $N$ Engl $J$ Med 2003;348:2472-4.

5. Stinco G, Ruscio M, Bergamo S, et al. Clinical features of 705 Borrelia burgdorferi seropositive patients in an endemic area of northern Italy. Scientific World J 2014:414505.

6. Puius YA, Kalish RA. Lyme arthritis: pathogenesis, clinical presentation, and management. Infect Dis Clin North Am 2008;22:289-300.

7. Steere AC, Gibofsky A, Patarroyo ME, et al. Chronic Lyme arthritis. Clinical and immunogenetic differentiation from rheumatoid arthritis. Ann Intern Med 1979;90:896-901.

8. Saraux A, Fautrel B, Maillefert JF, et al. Laboratory and imaging studies used by French rheumatologists to evaluate patients with early arthritis. J Rheumatol 2006;33:897-902.

9. Combe B, Benessiano J, Berenbaum F, et al. The ESPOIR cohort: a ten-year follow-up of early arthritis in France: methodology and baseline characteristics of the 813 included patients. Joint Bone Spine 2007;74:440-5.

10. Muller G, Cherasse A, Bour JB, et al. Diagnostic usefulness of routine Lyme serology in patients with early inflammatory arthritis in nonendemic areas. Joint Bone Spine 2003;70:119-21.

11. De Vries-Bouwstra JK, van Burgel ND, Vreeswijk T, et al Prevalence and clinical presentation of Lyme arthritis in a large cohort of patients with recent-onset arthritis. [abstract]. Arthritis Rheum 2013;65(Suppl 10):2809.

12. Coumou J, van der Poll T, Speelman P, et al. Tired of Lyme borreliosis. Lyme borreliosis in the Netherlands. Neth $\mathrm{J}$ Med 2011;69:101-11.

13. Coumou J, Hovius JW, van Dam AP. Borrelia burgdorferi sensu lato serology in the Netherlands: guidelines versus daily practice. Eur $J$ Clin Microbiol Infect Dis 2014;33:1803-8.

14. Blanc F. [Epidemiology of Lyme borreliosis and neuroborreliosis in France]. Rev Neurol (Paris) 2009;165:694-701.

15. Bunikis J, Barbour AG. Laboratory testing for suspected Lyme disease. Med Clin North Am 2002;86:311-40.

16. Tugwell P, Dennis DT, Weinstein A, et al. Laboratory evaluation in the diagnosis of Lyme disease. Ann Intern Med 1997;127:1109-23.

17. Sigal LH. Diagnosis of Lyme disease. JAMA 1995;274:1427-8.

18. Naesens R, Vermeiren S, Van Schaeren J, et al. False positive Lyme serology due to syphilis: report of 6 cases and review of the literature. Acta Clin Belg 2011;66:58-9.

19. DePietropaolo DL, Powers JH, Gill JM, et al. Lyme disease: what you should know. Am Fam Physician 2005;72:309.

20. Magnarelli LA, Miller JN, Anderson JF, et al. Cross-reactivity of nonspecific treponemal antibody in serologic tests for Lyme disease. J Clin Microbiol 1990;28:1276-9. 